\title{
The relationship between intermittent fasting and weight loss
}

\author{
Shih-Ching LO ${ }^{1,2 *}$ (c)
}

\section{Dear Editor,}

I have reviewed the article by Lima et al. ${ }^{1}$ entitled "Impact of intermittent fasting on body weight in overweight and obese individuals". In recent decades, intermittent fasting (IF) is currently a popular strategy for weight loss. Therefore, it is of great evidence-based practice to verify the relationship of IF in the body weight of overweight and obese individuals. The study of Lima et al. ${ }^{1}$ makes some valuable contributions. However, I'd like to confirm the details of this article. The authors indicate that table 1 shows 4 papers related to the impact of vitamin D in the glucose profile of pre-diabetic individuals in the headline. In fact, four studies were considered enrolled all assessed the effect of IF in overweight or obese individuals comparing
IF groups with calorie-restrictive diet (CRD) groups but not mentioned the impact of vitamin $\mathrm{D}$ in the glucose profile.

In addition, a review of the published literature reported improvements in cardiovascular and metabolic parameters (triglycerides, LDL-cholesterol particle size, blood pressure, fat mass, and C-reactive protein), mood/depression status, and quality of life, even longevity genes expression or DNA damage $^{2}$. Observational studies expanded on the fasting benefited with CAD and diabetes. IF with a high-protein diet is effective for weight loss were reported in few studies but not included vitamin $\mathrm{D}^{3}$. The description of the impact of vitamin $\mathrm{D}$ in the glucose profile of pre-diabetic individuals should be addressed in detail or revised.

\section{REFERENCES}

1. Lima CHR, Oliveira IKF, Frota KMG, Carvalho CMRG, Paiva AA, Campelo $V$, et al. Impact of intermittent fasting on body weight in overweight and obese individuals. Rev Assoc Med Bras (1992). 2020;66(2):222-6. https://doi.org/10.1590/1806-9282.66.2.222

2. Horne BD, Muhlestein JB, Anderson JL. Health effects of intermittent fasting: hormesis or harm? A systematic review.
Am J Clin Nutr. 2015;102(2):464-70. https://doi.org/10.3945/ ajcn.115.109553

3. Welton S, Minty R, O'Driscoll T, Willms H, Poirier D, Madden $S$, et al. Intermittent fasting and weight loss: systematic review. Can Fam Physician. 2020;66(2):117-25. PMID: 32060194 